\title{
Changes of Soil Properties with Various Soil Amendments in Saemangeum Reclaimed Tidal Saline Soil
}

\author{
Sanghun Lee*, Hong-Kyu Kim, Seon-Woong Hwang, and Kyeong-Bo Lee \\ National Institute of Crop Science, Rural Development Administration, Iksan 570-080, Korea
}

(Received: August 2 2013, Accepted: August 13 2013)

\begin{abstract}
Due to its high salt content and poor physical properties in reclaimed tidal lands, it is important to ameliorate soil physical properties to improve the efficiency of desalination. The objective of this study was to evaluate the changes of soil properties at Saemangeum reclaimed tidal saline soil with various soil amendments. Field experiment was conducted at Saemangeum reclaimed tidal land in Korea and the dominant soil series was Munpo series (coarse loamy, mixed, nonacid, Mesic, Typic, Fluvaquents). Woodchips, crushed-stone, oyster shell, coal bottom ash, and rice hull were added as soil amendments and mixed into surface soil to improve soil physical properties. There was large variability in soil hardness, but oyster shell treatment was significantly lower soil hardness at surface layer. Soil hardness was not significantly different below 15 cm depth. Infiltration rate was also significantly greater at oyster shell treatment. This may be due to the leaching of Ca ions from oyster shell and improved soil properties. However, there was no statistical significant difference of the soil bulk density, moisture content, and porosity. Improved physical properties increased desalinization rate in soil and retarded the resalinization rate when evapotranspiration rate was high. Although soil salinity was significantly decreased with oyster shell amendment, soil $\mathrm{pH}$ was increased that should be made up as a soil amendment. Our results indicated that oyster shell application increased infiltration rate and improved soil hardness, and thus oyster shell could be used to improve soil salinity level at Saemangeum reclaimed tidal saline soil.
\end{abstract}

Key words: Soil amendment, Reclaimed tidal land, Saline soil, Hardness, Infiltration

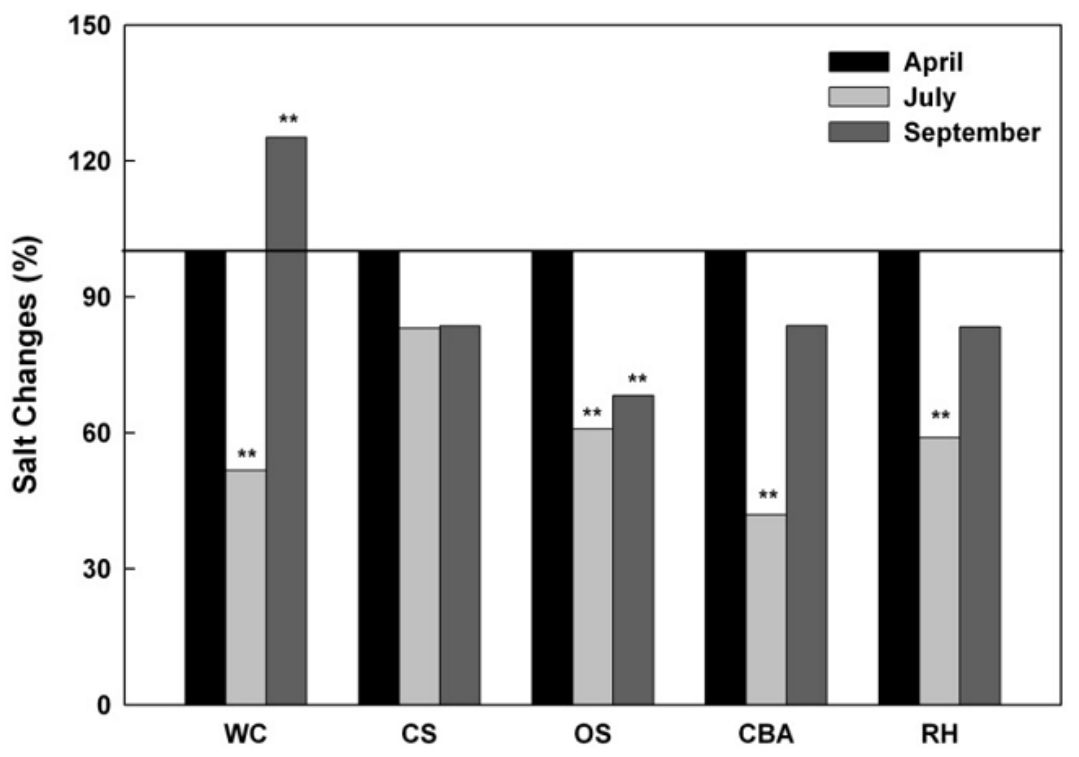

Oyster shell (OS) amendment was the most effective in reducing soil salt level during the plant growth period.

*Corresponding author : Phone: +82638402274, Fax: +82638402118, E-mail: sangusa@korea.kr

${ }^{\S}$ Acknowledgement: This study was carried out with the support of "Cooperative Research Program for Agriculture Science \& Technology Development (Project No. PJ008762)" Rural Development Administration, Republic of Korea. 


\section{Introduction}

The utilization of reclaimed tidal lands for crop production is great awareness to meet the needs of expanding population. However, reclaimed tidal land has poor physical and chemical properties due to its high salt contents and groundwater levels and thus low crop productivity is a common in these areas (Sohn et al., 2010; Yang et al., 2008). Also, low organic matter content and high sodium content gives rise to decrease soil porosity and infiltration rate (Ryu et al., 2009). Due to these reasons, reclaimed tidal land is recognized to be optimized as rice paddy field, but the interest in cultivation of upland crops is increasing due to their higher profitability and crop selfsufficiency.

To achieve a stable upland crop production in reclaimed tidal lands, removal of salts in rhizosphere must be a priority. Soluble salts can be easily removed through vertical water flow and thus saline soil can be improved by leaching them with clean water (Khoshgoftarmanesh et al., 2003; Lee et al., 2012a). Therefore, vertical water flow could be a viable method for reclamation of reclaimed tidal saline soils and crop production. However, soil profile in Saemangeum reclaimed tidal lands is structureless and thus the penetration rate and vertical water movement is relatively low (Ryu, 2010).

Soil physical properties are closely related with desalinization and resalinization process. It is well documented that the improvement of soil physical properties can increase infiltration rates and soil hardness which can influence on crop development by improvement of salt control (Cho and Kim, 1997; Ryu et al., 2009). To reduce salt levels in soil, it is important to keep up with high infiltration rate (Koo and Eun, 1988). Therefore, it is important to improve soil structure through soil amendments in reclaimed tidal lands. The question that arises is what types of soil amendments would be effective for Saemangeum reclaimed tidal saline soil.

Various materials including oyster shell, coal bottom ash, and rice hull have been widely evaluated as soil amendments (Lee et al., 2005; Lee et al., 2012b; Ryu, 2010). Shellfishery farm in Korea produces approximately 300 thousand tons of oyster shell each year. Around $40 \%$ of these oyster shells is recognized as a potential waste and has been dumped into the coast (Lee et al., 2005). Oyster shell has been evaluated for crop productivity by increasing soil fertility. For instance, Lee et al. (2012b) found that oyster shell was effective to improve soil microbe population and soil nutrients. Coal bottom ash is produced and deposited about 1.2 million tons per year in Korea (Lee, 2011). Although there is a concern over coal bottom ash on safety, the utilization of coal bottom ash is broadly investigated. Lee et al. (2010) showed that coal bottom ash application increased water and nutrient holding capacity on sandy soil, but the study by Ryu (2010) showed that coal bottom ash increased water flow rate. Rice hull and woodchip is a by-product during the process of rice and wood, which are producing about 700 thousand and 4.2 million tons every year in Korea (Keum, 2012; Park and Park, 2004). These organic materials can improve chemical and physical properties by improving aeration and drainage in soils. For instance, Seo et al. (2007) found that application of woodchips improved soil physical properties by reducing soil bulk density and increasing soil porosity. All these materials have the cheap price and regional availability, which is obviously one of the main strong points.

Although many studies were investigated the effect of soil amendment on soil properties, little information was revealed the effect of soil amendment on salt and water movement at reclaimed tidal saline soil. Therefore, the present study was carried out to investigate the effect of various soil amendments on the changes of the soil properties at Saemangeum reclaimed tidal saline soil.

\section{Materials and Methods}

Study Field Characteristics Field experiment was conducted at the research farm $\left(35^{\circ} 46^{\prime} \mathrm{N}, 126^{\circ} 37^{\prime} \mathrm{E}\right)$ in Saemangeum reclaimed tidal land for 2012. The average annual precipitation was $1,250 \mathrm{~mm}$, of which, on average, $54 \%$ fell between June and August. The annual temperature averaged $13{ }^{\circ} \mathrm{C}$ and ranged from a maximum of $26^{\circ} \mathrm{C}$ in August to a minimum of $-1{ }^{\circ} \mathrm{C}$ in January. Annual mean temperatures between May and August were slightly higher $\left(23.3\right.$ vs. $\left.21.8^{\circ} \mathrm{C}\right)$ than the long-term (recent 30 years) average temperature. Mean precipitation between May and August was similar (946 vs. $956 \mathrm{~mm}$ ) compared to the average, although the annual precipitation in 2012 was significantly higher $(1,468$ vs. $1,250 \mathrm{~mm})$ the longterm average.

The dominant soil series at the experimental site was Munpo soil (coarse loamy, mixed, nonacid, Mesic, Typic, Fluvaquents) that comes from the fluvio-marine deposit. The surface $(0-20 \mathrm{~cm})$ soil had $\mathrm{pH}$ of 6.2 and low organic matter $\left(1.9 \mathrm{~g} \mathrm{~kg}^{-1}\right)$ and exchangeable calcium content (1.1 $\left.\mathrm{cmol}_{\mathrm{c}} \mathrm{kg}^{-1}\right)$. Study soil had a relatively high soil EC (electrical conductivity, $21.4 \mathrm{dS} \mathrm{m}^{-1}$ at the surface layer) because study field was rarely cultivated since building up in 2006. Physical and chemical properties of study soil in pre-experiment are shown in Table 1.

Treatments Soil amendments were selected based on 
Table 1. Physico-chemical properties of the experimental soil before the experiments.

\begin{tabular}{|c|c|c|c|c|c|c|c|c|c|c|c|c|c|}
\hline \multirow{2}{*}{ Soil } & \multirow{2}{*}{$\mathrm{pH}$} & \multirow{2}{*}{$\mathrm{EC}$} & \multirow{2}{*}{$\mathrm{OM}$} & \multirow{2}{*}{$\begin{array}{l}\text { Avail. } \\
\mathrm{P}_{2} \mathrm{O}_{5}\end{array}$} & \multicolumn{4}{|c|}{ Soluble cations } & \multirow{2}{*}{$\mathrm{BD}$} & \multicolumn{3}{|c|}{ Particle size distribution } & \multirow{2}{*}{$\begin{array}{c}\text { Soil } \\
\text { Texture }\end{array}$} \\
\hline & & & & & $\mathrm{K}$ & $\mathrm{Ca}$ & $\mathrm{Mg}$ & $\mathrm{Na}$ & & Sand & Silt & Clay & \\
\hline$(\mathrm{cm})$ & $1: 5, \mathrm{H}_{2} \mathrm{O}$ & $\mathrm{dS} \mathrm{\textrm {m } ^ { - 1 }}$ & $\mathrm{g} \mathrm{kg}^{-1}$ & $\mathrm{mg} \mathrm{kg}^{-1}$ & \multicolumn{4}{|c|}{--- $\left(\mathrm{cmol}_{\mathrm{c}} \mathrm{kg}^{-1}\right)$} & $\mathrm{Mg} \mathrm{m}^{-3}$ & \multicolumn{3}{|c|}{ 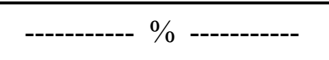 } & \\
\hline $0-20$ & 6.2 & 21.4 & 1.9 & 122 & 1.52 & 1.1 & 5.6 & 16.8 & 1.55 & 59 & 29 & 12 & $\mathrm{SL}^{\dagger}$ \\
\hline $20-40$ & 7.3 & 15.3 & 1.6 & 32 & 1.17 & 1.3 & 4.1 & 13.4 & 1.52 & - & - & - & - \\
\hline $40-60$ & 8.1 & 14.5 & 1.8 & 37 & 1.34 & 1.3 & 3.9 & 12.5 & 1.50 & - & - & - & - \\
\hline $60-80$ & 8.7 & 13.0 & 1.7 & 44 & 1.43 & 1.2 & 3.3 & 12.1 & 1.49 & - & - & - & - \\
\hline $80-100$ & 8.8 & 12.7 & 2.0 & 55 & 1.46 & 1.2 & 3.3 & 11.6 & 1.47 & - & - & - & - \\
\hline
\end{tabular}

${ }^{\dagger} \mathrm{SL}$, sandy loam

Table 2. The height of maize at 60 days after planting with various soil amendments.

\begin{tabular}{cccccccccc}
\hline \hline & $\mathrm{WC}^{\dagger}$ & $\mathrm{CS}$ & $\mathrm{OS}$ & $\mathrm{CBA}$ & $\mathrm{RH}$ & Control & $p$-value & LSD $_{0.05}$ \\
\hline Height $(\mathrm{cm})$ & 30.4 & 37.2 & 27.3 & 33.6 & 34.2 & 33.6 & 0.0547 & $\mathrm{NS}^{\ddagger}$ \\
\hline
\end{tabular}

${ }^{\dagger}$ WC, woodchip; CS, crushed-stone; OS, oyster-shell; CBA, coal bottom-ash; RH, rice hull.

${ }^{\ddagger} \mathrm{NS}$, not significant at $95 \%$ level.

its regional availability and economic feasibility. Woodchips (1-10 cm sized), crushed-stone $(13 \mathrm{~mm})$, oyster shell $(5-8$ $\mathrm{mm})$, coal bottom ash $(2-10 \mathrm{~mm})$, and rice hull were collected from a Buan regional sawmill, Buan stone pit, Seosan shellfishery farm, Boryeong thermoelectric power plant, and Buan regional rice process complex, respectively. All materials were air-dried until they were applied into surface soil. Each material was prepared at volume basis $\left(80 \mathrm{~m}^{3} \mathrm{ha}^{-1}\right.$ ratio) and mixed into the each plot $(60$ $\mathrm{m}^{2}$ ). After applying soil amendments, soils were plowed with a plot combine. Silage maize (Zea mays L.) was planted on April 28, 2012 at $3 \mathrm{~kg} \mathrm{ha}^{-1}$ seeding rate with $60 \times 20 \mathrm{~cm}$ row spacing. All treatment was fertilized with 200-150-150 (N-P $\left.\mathrm{P}_{2} \mathrm{O}_{5}-\mathrm{K}_{2} \mathrm{O}\right) \quad \mathrm{kg} \mathrm{ha}^{-1}$. Urea with $50 \%$ recommendation rate was broadcasted before planting and the rest was applied at V-5 stage.

Analysis of Soil Properties In this study, soil analysis was conducted based on standard methods by NAIST (NIAST, 2000). Soils were air-dried, passed through a 2-mm sieve, and then used for analyses. Soil $\mathrm{pH}$ and EC was determined using a 1:5 soil/water suspension using 5 $\mathrm{g}$ of soil with $\mathrm{pH}$ meter (Beckman PH1560, USA) and conductivity meter (Orion 162A, USA), respectively. Organic matter content was measured by Tyurin method (NIAST, 2000) and total carbon (C) content was determined by dry combustion method using a Vario Max CNS elemental analyzer (Elementar Instrument, Germany). Available phosphorus $\left(\mathrm{P}_{2} \mathrm{O}_{5}\right)$ was determined by Lancaster method (NIAST, 2000) and particle size distribution was analyzed by using ASTM 152H hydrometer after dispersion with $5 \%$ sodium hexametaphosphate. Exchangeable cations were extracted by $1 \mathrm{~N}-\mathrm{NH}_{4} \mathrm{OAc}$ (adjusted $\mathrm{pH}$ 7.0) and quantified by inductively coupled plasma-optical emission spectrometer (Varion Vista-MPX, Australia). For bulk density, soil core $\left(100 \mathrm{~cm}^{3}\right.$ volume) with a diameter of 5 $\mathrm{cm}$ were collected and dried at $105^{\circ} \mathrm{C}$ for $24 \mathrm{hrs}$ in a drying oven. Soil hardness was determined by soil hardness meter (Daiki DIK-5530, Japan) and averaged with fivetime readings. Infiltration rate was measured by tension infiltrometer that was designed according to the specifications described by Perroux and White (1988).

Statistical Analysis The data was statistically analyzed using analysis of variance (ANOVA) with the JMP statistical program (SAS institute ver. 5.0). Means between treatments were compared by least significant difference and Tukey-Kramer HSD at 95\% level when the F-test was statistically significant.

\section{Results and Discussion}

Plant Growth Initial soil electrical conductivity in study soil was $21.4 \mathrm{dS} \mathrm{m}^{-1}$, which is far beyond the threshold for maize yield reduction (Ayers and Westcot, 1985). Thus, the maize growth at establishment stage was poor in visual observation, even though most of maize was germinated. The height of maize at 60 days after planting was averaged $32.7 \mathrm{~cm}$ (Table 2). However, analysis of variance showed that there was no significant difference in maize height among treatments with soil amendments. All the maize withered in July due to high salt content in soil and thus we could not further investigate the effect of soil amendments on plant growth 
and yield.

Changes in Soil Salinity Salt distribution in soil profile before the commencement with various soil amendments showed that electrical conductivity at surface layer was $21.4 \mathrm{dS} \mathrm{m}^{-1}$, which was decreased with increasing soil depth. It may be due to the upward movement of soluble salts by capillary rise, which can be supported by soluble cations throughout soil profile. In July, soil electrical conductivity at soil surface was decreased compared to the April, regardless of the type of soil amendments (Fig. 1). The decline in electrical conductivity may be result of leaching by heavy precipitation during the rainy season in Korea. The depression in electrical conductivity was the greatest in coal bottom ash treatment. This result indicates that coal bottom ash was the most effective in depressing

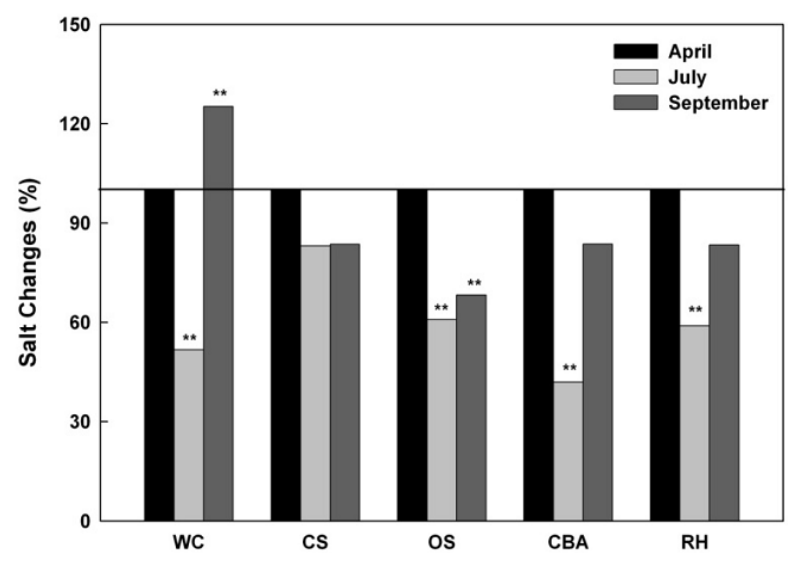

Fig. 1. Changes of soil salt ratio (Salt concentration in July or September divided by the control) at the reclaimed saline soil $(0-20 \mathrm{~cm})$ with various soil amendments.

WC, woodchip; CS, crushed-stone; OS, oyster-shell; CBA, coal bottom-ash; RH, rice hull.

* denotes the salt concentration at each sampling date was significantly different compared to the salt concentration in control at $95 \%$ level. soil electrical conductivity in rainy season. This result can be supported by the findings that hydraulic conductivity of coal bottom ash was 16-fold faster than the sand (Ryu, 2010). He found that coal bottom ash can increase the porosity in reclaimed soil and removal of salts was very effective. However, in September, when high evaporation and low precipitation was observed, soil salts were increased at three (woodchip, coal bottom ash and rice hull) out of five treatments. It suggests that insufficient amounts of water input to leach salts would result in a significant movement of salt from sub-surface to surface layer. Especially, the application of wood chip had a higher electrical conductivity compared to the control. However, crushed-stone and oyster shell treatment did not change the salt level, indicating that resalinization was depressed with these treatments. Although the depression of salt with oyster shell amendment was less than the treatment of wood chip and coal bottom ash, little salt accumulation was within the surface layer in September. These results indicate that oyster-shell amendment was effective in salt controls at Saemangeum reclaimed saline soil during the crop development period.

Salt distribution at surface layer following the mixture with different types of soil amendments is shown in Table 3. The electrical conductivity in oyster shell treatment was significantly reduced from 21.4 to $16.9 \mathrm{dS}$ $\mathrm{m}^{-1}$. Although rice hull application slightly increased electrical conductivity, but there was not changed in the rest soil amendments. Soluble sodium and magnesium contents were significantly increased with rice hull applications. Soluble and exchangeable calcium was increased with oyster shell amendment, but exchangeable sodium content was not significantly changed with oyster shell. The salt in surface layer was displaced downward (11.8 cmol kg-1 in 0-20 cm depth vs. $14.4 \mathrm{cmol} \mathrm{kg}^{-1}$ in 20-40 $\mathrm{cm}$ depth) with application of oyster shell through the soil. For a long time, gypsum has been recognized the most effective soil amendment because the soil profile

Table 3. Chemical properties of the experimental soil $(0-20 \mathrm{~cm})$ after treating soil amendments at Saemangeum reclaimed tidal saline soil.

\begin{tabular}{lcccccccc}
\hline \hline \multirow{2}{*}{ Type } & $\mathrm{pH}$ & $\mathrm{EC}$ & $\mathrm{OM}$ & $\mathrm{Av} . \mathrm{P}_{2} \mathrm{O}_{5}$ & \multicolumn{3}{c}{ Soluble cations $\left(\mathrm{cmol}_{\mathrm{c}} \mathrm{kg}^{-1}\right)^{\ddagger}$} \\
\cline { 7 - 9 } & $(1: 5)$ & $\left(\mathrm{dS} \mathrm{m}^{-1}\right)$ & $\left(\mathrm{g} \mathrm{kg}^{-1}\right)$ & $\left(\mathrm{mg} \mathrm{kg}^{-1}\right)$ & $\mathrm{K}$ & $\mathrm{Ca}$ & $\mathrm{Mg}$ & $\mathrm{Na}$ \\
\hline $\mathrm{WC}^{\dagger}$ & 6.8 & 19.3 & 1.7 & 111 & $0.69(0.75)$ & $0.30(0.66)$ & $1.60(2.51)$ & $13.47(2.03)$ \\
$\mathrm{CS}$ & 6.6 & 18.3 & 2.0 & 100 & $0.60(0.69)$ & $0.35(0.86)$ & $1.30(2.39)$ & $13.84(2.00)$ \\
$\mathrm{OS}$ & 8.2 & 16.9 & 1.8 & 150 & $0.57(0.75)$ & $0.51(2.18)$ & $1.27(2.50)$ & $13.45(1.94)$ \\
$\mathrm{CBA}$ & 6.6 & 19.8 & 1.8 & 85 & $0.61(0.68)$ & $0.31(0.63)$ & $1.73(2.56)$ & $14.67(2.11)$ \\
$\mathrm{RH}$ & 6.7 & 22.8 & 1.4 & 115 & $0.70(0.71)$ & $0.35(0.59)$ & $2.39(2.86)$ & $19.42(2.19)$ \\
Control & 6.7 & 20.3 & 1.6 & 96 & $0.63(0.66)$ & $0.42(0.68)$ & $2.57(2.95)$ & $14.92(1.97)$ \\
\hline
\end{tabular}

${ }^{\dagger}$ WC, woodchip; CS, crushed-stone; OS, oyster-shell; CBA, coal bottom-ash; RH, rice hull.

${ }^{\ddagger}$ Exchangeable cations in parenthesis 


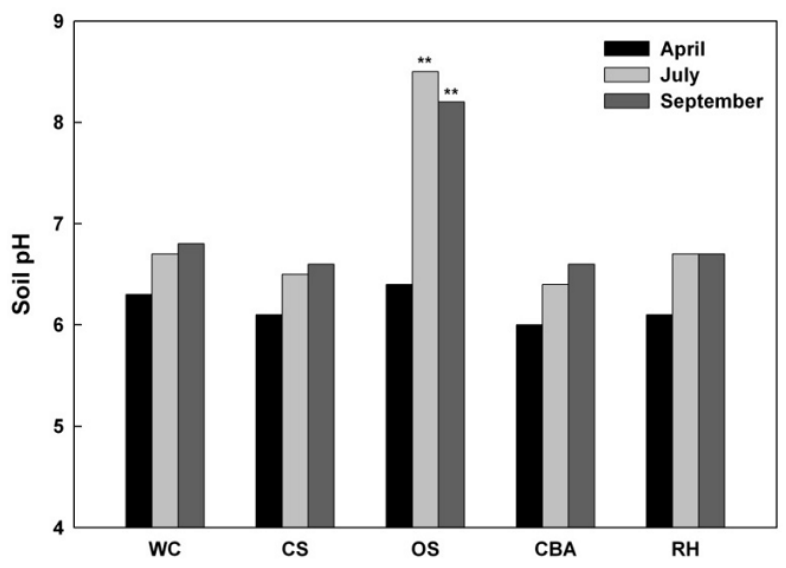

Fig. 2. Changes of soil $\mathrm{pH}$ at the reclaimed saline soil (0-20 cm) with various soil amendments.

WC, woodchip; CS, crushed-stone; OS, oyster-shell; CBA, coal bottom-ash; RH, rice hull.

** denotes the soil $\mathrm{pH}$ at each sampling date was significantly different compared to the soil $\mathrm{pH}$ in April at 95\% level.

can be reduced salt content and sodium adsorption ratio in gypsum treated soil (Ryu et al., 2010). However, soluble sodium was much higher contents in this study soil and thus improved water flow could be reclaimed soil properties. Therefore, oyster shell would be a good alternative choice for improving soil properties and salt control. Although soil salinity was significantly decreased with oyster shell, soil $\mathrm{pH}$ was significantly increased with oyster shell amendment (Fig. 2). This result is in agreement with results reported by many investigators who also observed that soil $\mathrm{pH}$ significantly increased with application of oyster shell (Lee et al., 2005, Lee et al., 2012b; Ok et al., 2011).

\section{Changes in Soil Hardness and Infiltration Soil} hardness averaged 0.95 and $2.4 \mathrm{MPa}$ in surface $(0-15 \mathrm{~cm})$ and sub-surface $(15-30 \mathrm{~cm})$ layer, respectively (Table 4). The coefficient of variation of soil hardness was $26 \%$ at soil surface, but the value was $9.5 \%$ at sub-surface layer. As expected, this result indicates that soil hardness had a wide variation near the soil surface. The result also showed that oyster shell amendment significantly lowered soil hardness compared to the untreated soil at surface layer. The hardness at sub-surface was significantly higher

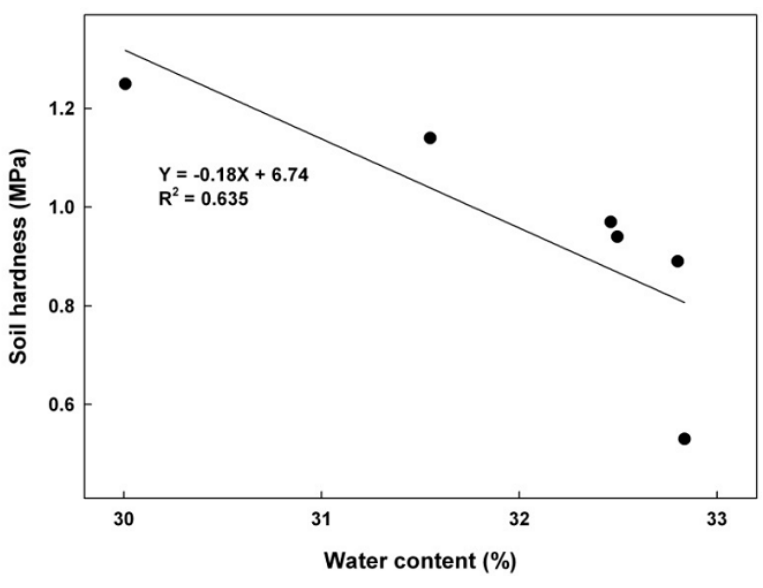

Fig. 3. Comelation between soil hardness and soil water content in surface layer.

than surface layer, but there was no significant difference among soil amendment treatments. The soil hardness values in sub-surface layer were exceeded the limiting values $(>2.0 \mathrm{MPa})$ for optimum growth of crops (Braunack et al., 2012). This result may indicate that soil amendments were incorporated with soil surface due to the plowing depth and the effect was diminished at a deeper depth. Soil hardness is a measurement of soil strength to resist mechanical distribution that is influenced by soil moisture and soil density (Jia et al., 2008; Park et al., 2006). Cho and Kim (1997) also found that soil hardness was highly correlated with bulk density and soil water content. In this study, soil hardness was significantly correlated ( $\mathrm{y}=$ $\left.-0.18 \mathrm{x}+6.74, \mathrm{R}^{2}=0.635\right)$ with water content at soil surface (Fig. 3). This result shows that soil is more compacted when it becomes dry. However, soil hardness had no significant correlations with bulk density at both layers and soil amendments did not affect on soil porosity under a given condition (Table 5).

Saline soil could be improved if more water were passed through soil profile. Infiltration rate was measured to describe the penetration of water through the soil surface. Infiltration rate had wide variations ranged from 0.55 in control to $6.36 \mathrm{~cm} \mathrm{hr}^{-1}$ in oyster shell treatment (Table 6). Statistically, there was a significant difference in the infiltration rate measured in this study. However, when soil bulk density was at $1.47 \mathrm{Mg} \mathrm{m}^{-3}$, infiltration rate was lower than average. It is well reported that soils

Table 4. Soil hardness at Saemangeum reclaimed tidal saline soil in pressure (MPa).

\begin{tabular}{lllllllll}
\hline \hline Depth $(\mathrm{cm})$ & $\mathrm{WC}^{\dagger}$ & $\mathrm{CS}$ & OS & CBA & RH & Control & $p$-value & LSD $_{0.05}$ \\
\hline $0-15$ & 1.25 & 0.89 & 0.53 & 0.97 & 1.14 & 0.94 & 0.0342 & 0.39 \\
$15-30$ & 2.60 & 2.68 & 2.50 & 2.23 & 2.08 & 2.37 & 0.1848 & NS $^{\ddagger}$ \\
\hline
\end{tabular}

${ }^{\dagger}$ WC, woodchip; CS, crushed-stone; OS, oyster-shell; CBA, coal bottom-ash; RH, rice hull.

${ }^{\ddagger} \mathrm{NS}$, not significant at $95 \%$ level. 
Table 5. Soil bulk density and three-phase distribution at Saemangeum reclaimed tidal saline soil (0-15 $\mathrm{cm})$ with various soil amendments.

\begin{tabular}{cccccc}
\hline \hline \multirow{2}{*}{ Types } & \multirow{2}{*}{ Bulk density $\left(\mathrm{Mg} \mathrm{m}^{-3}\right)$} & Solid & Liquid & Gas & \multirow{2}{*}{ Porosity (\%) } \\
\cline { 3 - 5 } WC $^{\dagger}$ & 1.43 & 54 & 30 & 16 & 46 \\
$\mathrm{CS}$ & 1.48 & 52 & 33 & 15 & 43 \\
$\mathrm{OS}$ & 1.42 & 54 & 33 & 13 & 46 \\
$\mathrm{CBA}$ & 1.45 & 55 & 32 & 13 & 45 \\
$\mathrm{RH}$ & 1.38 & 52 & 32 & 16 & 48 \\
Control & 1.43 & 54 & 33 & 14 & 46 \\
-value & 0.7560 & 0.7519 & 0.2893 & 0.3716 & 0.7519 \\
LSD & $\mathrm{NS}$ & $\mathrm{NS}$ & $\mathrm{NS}$ & $\mathrm{NS}$ & $\mathrm{NS}^{\ddagger}$ \\
\hline
\end{tabular}

${ }^{\dagger}$ WC, woodchip; CS, crushed-stone; OS, oyster-shell; CBA, coal bottom-ash; RH, rice hull.

${ }^{\dagger} \mathrm{NS}$, not significant at $95 \%$ level.

Table 6. Water infiltration rate at Saemangeum reclaimed tidal saline soils with various water contents.

\begin{tabular}{cccccccccc}
\hline \hline \multirow{2}{*}{$\begin{array}{c}\text { Volumetric } \\
\text { Water Content }\end{array}$} & $\begin{array}{c}\text { Bulk Density } \\
\left(\mathrm{Mg} \mathrm{m}^{-3}\right)\end{array}$ & $\mathrm{WC}^{\dagger}$ & $\mathrm{CS}$ & $\mathrm{OS}$ & $\mathrm{CBA}$ & $\mathrm{RH}$ & Control & $p$-value & LSD $_{0.05}$ \\
\hline 0.25 & 1.32 & 1.76 & 1.00 & 6.36 & 1.39 & 2.52 & 0.55 & \\
0.32 & 1.47 & 1.59 & 0.93 & 2.20 & 1.66 & 1.07 & 0.74 & \\
0.27 & 1.45 & 1.75 & 0.84 & 2.59 & 1.17 & 1.28 & 0.88 & \\
& & 1.70 & 0.92 & 3.72 & 1.42 & 1.62 & 0.72 & 0.0372 & $1.78^{\ddagger}$ \\
\hline
\end{tabular}

${ }^{\dagger}$ WC, woodchip; CS, crushed-stone; OS, oyster-shell; CBA, coal bottom-ash; RH, rice hull.

${ }^{\ddagger} \mathrm{NS}$, not significant at $95 \%$ level.

with high sodium content usually had a lower hydraulic conductivity than in soil with lower sodium content (Lee et al., 2012a; Rao and Mathew, 1995; Ryu et al., 2009). This result may be related to the dispersion and deflocculation of clay minerals. Infiltration rate was increased with oyster shell amendment regardless of volumetric water content in soils. This result is probably due to the reduction of salt level in soils. This finding is in agreement with results reported by several investigators who also observed that oyster shell application lowered salt levels and improved water flow in soil. For instance, Koo and Eun (1988) found that the reduction of sodium contents in soil can increase the hydraulic conductivity. Soluble salt contents and exchangeable sodium content should be lowered to reclaim the saline soil. The amounts and types of adsorbed cations are influenced on water flow (Park and O'Connor, 1983; Rao and Mathew, 1995; Yoo and Lee, 1988). Especially sodium is strongly influenced on water flow in soils since water flow is strongly influenced by the valence and the hydrated radius of adsorbed cations. In this study, application of oyster shell increased calcium content in soil and thus improved to leach soluble salts, especially sodium, in soil. Application of soil amendments increased in hydraulic conductivity and mixing with calcium compounds was more effective for desalinization (Koo and Eun, 1988; Yoo and Lee, 1988). Although infiltration rates are influenced by various soil factors including water potential and porosity, we could not find any evidence on filtration rate in this study.

\section{Conclusions}

Our results indicated that Saemangeum reclaimed saline soil is likely to response to the application of oyster shell, which might be desirable to improve infiltration rate and salt control. Although soil salinity was significantly decreased with oyster shell amendment, soil $\mathrm{pH}$ was increased that should be made up as a soil amendment. Further investigation needs to verify the effect of soil amendments on soil properties and their economic evaluations.

\section{References}

Ayers, R.S., and D.W. Westcot. 1985. Water quality for agriculture. FAO irrigation and drainage paper \#29. Rev. 1. U.N. Rome.

Braunack, M., J. Price, and D. Hodgson. 2012. Soil compaction under cotton pickers: preliminary results. $16^{\text {th }}$ 
Australian Agronomy Conference. Armidale, NSW. Austria Cho, J.H., and K.R. Kim. 1997. Effects of bulk density, volumetric water and gravel contents on hardness in prepared sandy loam. Korean J. Soil Sci. Fert. 30:46-50. Jia, X., T.F. Scherer, T.M. DeSutter, and D.D. Steele. 2008. Change of soil hardness and soil properties due to tile drainage in the Red River Valley of the North. 2008 ASABE Annual International Meeting. Providence, RI.

Keum, D.H. 2012. Development of new grain drying system and electric power plant using the husk energy for rice processing complex. RDA, Suwon. Korea.

Khoshgoftarmanesh, A.H., H. Shariatmadari, and R. Vakil. 2003. Reclamation of saline soils by leaching and barley production. Commun. Soil Sci. Plant Anal. 34:2875-2883.

Koo, J.W., and C.H. Eun. 1988. Changes of hydraulic conductivity during desalinization of reclaimed tidelands. J. Korean Soc. Agri. Engineers. 30:85-93.

Lee, C.H., J.Y. Lee, B.H. Ha, and P.J. Kim. 2005. Increased available phosphorus by shell meal fertilizer application in upland soil. Korean J. Soil Sci. Fert. 38:52-57.

Lee, J.Y. 2011. Assessment of bottom ash amendment on soil turfgrass qualities in golf course. Doctoral dissertation. Kangwon National University. Chuncheon, Korea.

Lee, J.Y., C.H. Lee, Y.S. Yoon, B.H. Ha, B.C. Jang, K.S. Lee, D.K. Lee, and P.J. Kim. 2005. Effects of oyster shell meal on improving spring chinese cabbage productivity and soil properties. Korean J. Soil Sci. Fert. 38:274-280.

Lee, S., D.Y. Chung, S.W. Hwang, K.B. Lee, C.H. Yang, and H.K. Kim. 2012a. Hydraulic and solute breakthrough from salt accumulated soils under various head pressures. Korean J. Soil Sci. Fert. 45:717-724.

Lee, Y.H., Y.K. Sohn, S.T. Lee, J.Y. Heo, M.K. Kim, E.S. Kim, W.D. Song, D.H. Kim, and Y.S. Ok. 2012b. Effect of oyster shell lime on barley growth and soil microbe in an upland soil. Korean J. Soil Sci. Fert. 45:610-613.

NIAST. 2000. Methods of soil chemical analysis. National Institute of Agricultural Science and Technology. RDA. Suwon, Korea.

Ok, Y.S., J.E. Lim, and D.H. Moon. 2011. Stabilization of Pb and $\mathrm{Cd}$ contaminated soils and soil quality improvements using waste oyster shells. Environ. Geochem. Health.
33:83-91.

Park, C.S., and G.A., O'Connor. 1983. Salinity effects on the hydraulic conductivity of uplands. J. Korean Soc. Soil Sci. Fert. 16:7-13.

Park, C.S., S.H. Yang, G.J. Lee, J.T. Lee, H.M. Kim, S.H. Park, D.H. Kim, A.Y. Jung, and S.W. Hwang. 2006. Spatial variability of soil moisture content, soil penetration resistance and crop yield on the leveled upland in the reclaimed highland. Korean. J. Soil Sci. Fert. 39:123-135.

Perroux, K. and I., White. 1988. Designs for disc permeameters. Soil Sci. Soc. Am. J. 52:1205-1215.

Rao, S.N., and P.K. Mathew. 1995. Effects of exchangeable cations on hydraulic conductivity of a marine clay. Clays and Clay Minerals. 43:433-437.

Ryu, J.H. 2010. Solute movement in multi-layered reclaimed soils with macroporous subsurface layer utilizing a coal bottom ash. Ph.D. dissertation. Chungnam National University. Daejeon, Korea.

Ryu, J.H., D.Y. Chung, C.H. Yang, S.B. Lee, W.Y. Choi, and S.J. Kim. 2009. Effect of $\mathrm{Na}$ ion on changes in hydraulic conductivity and chemical properties of effluent of reclaimed sandy soil column. Korean J. Soil Sci. Fert. 42:454-459.

Seo, Y.H., S.J. Lim, S.K. Kim, and Y.S. Jung. 2007. Effect of rice straw and woodchip application on greenhouse soil properties and vegetable crops production. Korean J. Soil Sci. Fert. 40:4-11.

Sohn, Y.M., H.T. Kim, G.Y. Jeon, J.D. Song, J.H. Lee, and M.E. Park. 2010. Effect of flooding treatment on the desalting efficiency and the growth of soiling and forage crops in a sandy soil of the Iweon reclaimed tidal land in Korea. Korean J. Soil Sci. Fert. 43:16-24.

Yang, C.H., C.H. Yoo, J.H. Jung, B.S. Kim, W.K. Park, J.H. Ryu, T.K. Kim, J.D. Kim, S.J. Kim, and S.H. Baek. 2008. The change of physic-chemical properties of paddy soil in reclaimed tidal land. Korean J. Soil Sci. Fert. 41:94-102.

Yoo, S.H., and S.M. Lee. 1988. Laboratory study on changes in hydraulic conductivity and chemical properties of effluent of soil during desalinization. J. Korean Soc. Soil Sci. Fert. 21:3-10. 